\title{
Monitoring Healthy People 2010
}

Arthritis Management Objectives:

\section{Education and Clinician Counseling for Weight Loss and Exercise}

\author{
Barbara T. Do, MSPH \\ Jennifer M. Hootman, PbD, ATC \\ Charles G. Helmick, MD \\ Teresa J. Brady, PbD \\ Centers for Disease Control and \\ Prevention, Atlanta, Georgia
}

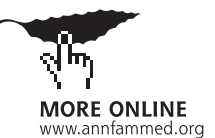

Conflicts of interest: authors report none

\section{CORRESPONDING AUTHOR}

Charles G. Helmick, MD

Centers for Disease Control

and Prevention

4770 Buford Hwy, MS K-51

Atlanta, GA 30341

cgh1@cdc.gov

\begin{abstract}
PURPOSE Our goal was to monitor the progress of 3 Healthy People 2010 (HP2010) objectives encouraging self-management education and clinician counseling for weight loss and physical activity among adults with doctor-diagnosed arthritis.

METHODS Using the national 2002 and 2006 National Health Interview Survey (NHIS) and state-based 2003 and 2007 Behavioral Risk Factor Surveillance System (BRFSS), we estimated the change in proportion of persons counseled for each objective, overall and by selected characteristics.

RESULTS Nationally, the proportion of overweight and obese adults with doctordiagnosed arthritis who were counseled by their clinician to lose weight to lessen their arthritis symptoms increased significantly from $35.0 \%$ (95\% confidence interval [Cl], 32.8\%-37.2\%) in 2002 to $41.3 \%(95 \% \mathrm{Cl}, 38.7 \%-44.0 \%)$ in 2006 but have yet to reach the 2010 target of $46 \%$. There was no change in the proportion of adults with doctor-diagnosed arthritis who had ever taken a selfmanagement education class (approximately 11\%) or who had been counseled to engage in physical activity (approximately 52\%), whose targets for 2010 are 13\% and $67 \%$, respectively. States had variable findings.
\end{abstract}

CONCLUSIONS Nationally, significant progress has been made by clinicians for weight counseling of overweight and obese adults with doctor-diagnosed arthritis but not for the other 2 arthritis management objectives. Because clinician counseling can have important effects on the latter, this discrepancy suggests a need to focus on barriers to physician counseling for these outcomes.

Ann Fam Med 2011;9:136-141. doi:10.1370/afm.1210.

\section{INTRODUCTION}

rthritis is one of the most common chronic conditions found in the
US population. It currently affects 46 million US adults ${ }^{1}$ and is pro-
jected to increase $45 \%$ by $2030 .{ }^{2}$ It is the most common cause of disability in the United States, substantially affecting a person's quality of life as a result of work and activity limitations, which subsequently affects the economy. 3,4

Professional health care groups ${ }^{5-8}$ recommend targeting 3 areas of arthritis management: weight counseling of overweight and obese patients, physical activity counseling, and self-management education. Being overweight or obese is common $(66 \%)^{9}$ among adults with doctor-diagnosed arthritis, and evidence shows that losing weight can diminish disability. ${ }^{10}$ Physical activity is recognized to reduce pain and disability and to increase function, ${ }^{11-13}$ whereas self-management education for arthritis has 
been shown to improve the health of an adult with doctor-diagnosed arthritis by $15 \%$ to $30 \%$ more than medication alone..$^{14}$ To monitor intermediate steps necessary to address these 3 areas successfully, 3 arthritis objectives (weight counseling among persons who were overweight and obese, physical activity counseling, and arthritis education) were included in Healthy People 2010 (HP2010), the nation's health objectives. These objectives require that by 2010, the proportion of adults with doctor-diagnosed arthritis having had arthritis education reach $13 \%$, and those receiving counseling for physical activity reach $67 \%$ and for weight counseling (among those overweight or obese) reach $46 \%$. Because of their nonpharmacologic, noninvasive approach, these recommendations were anticipated to be well received by primary care physicians, ${ }^{15}$ who handle more than $50 \%$ of arthritis clinic visits. ${ }^{16}$

In 2002-2003, the Centers for Disease Control and Prevention (CDC) first analyzed data dealing with these 3 HP2010 arthritis management objectives by using the National Health Interview Survey (NHIS) and the state-based Behavioral Risk Factor Surveillance (BRFSS) survey. ${ }^{17}$ This analysis updates national progress toward targets for the 3 arthritis management objectives overall and by selected characteristics.

\section{METHODS}

We used data on adults aged 18 years and older with doctor-diagnosed arthritis from the 2002 and 2006 NHIS to make national estimates and from the 2003 and 2007 BRFSS to make state-based estimates. Each survey used identical questions to monitor the 3 HP2010 arthritis management objectives. Data collection procedures and survey instruments are approved by the CDC Institutional Review Board annually.

\section{Survey Designs and Data}

Details about the survey structure and sample design of NHIS and BRFSS can be found online and in print. ${ }^{18,19}$ In brief, the NHIS is an annual, in-person survey designed to be representative of the civilian, noninstitutionalized population of the United States. BRFSS is an annual, state-based random-digit-dialed telephone survey designed to be representative of the civilian, noninstitutionalized adults aged 18 years and older of each state.

\section{Measures}

Doctor-diagnosed arthritis was defined as a yes answer to the following question: "Have you ever been told by a doctor or other health professional that you have some form of arthritis, rheumatoid arthritis, gout, lupus, or fibromyalgia?" Those answering yes were then asked about weight counseling, physical activity counseling, and arthritis education.

The national prevalence of adults with doctordiagnosed arthritis was calculated by using the NHIS civilian, noninstitutionalized population as the denominator. For both NHIS and BRFSS, the proportions reported receiving physical activity counseling and arthritis education were calculated by using the total number of respondents who had doctor-diagnosed arthritis as the denominator. The proportion reporting receiving weight counseling was calculated by using the total number of respondents with doctor-diagnosed arthritis who were overweight or obese as the denominator. Proportion estimates for each objective were calculated for the overall target population for subgroups characterized by the following self-reported characteristics: age, sex, race/ethnicity, education level, body mass index, physical activity levels, and arthritisattributable activity limitation. Physical activity and inactivity levels were defined by participation in any leisure-time physical activity assessed by 6 questions on frequency and duration of leisure-time physical activity. Persons with doctor-diagnosed arthritis were classified as having arthritis-attributable activity limitation if they answered yes to the question: "Are you now limited in any way in any of your usual activities because of arthritis or joint symptoms?"

\section{Statistical Analyses}

Prevalence and proportion estimates and 95\% confidence intervals were calculated by using statistical weights in SUDAAN (RTI International, Research Triangle Park, North Carolina) to account for the complex sample designs of both NHIS and BRFSS. To be consistent with HP2010 procedures, weighted NHIS and BRFSS data were age-standardized (18-44, 45-64, and 65 years and older) to the projected 2000 US population. ${ }^{19}$ We analyzed proportion differences between baseline and follow-up by conducting $z$ tests for 2 proportions.

\section{RESULTS}

The reported prevalence of doctor-diagnosed arthritis was $20.7 \%$ of US adults, using age-standardized 2006 NHIS data (Table 1). As seen in other studies, a higher prevalence of doctor-diagnosed arthritis was observed in older adults, women, and those who were overweight or obese, whereas a lower prevalence was observed in those of Hispanic or other race/ethnicity. ${ }^{1-3}$

Nationally, the proportion of weight counseling of overweight and obese adults with doctor-diagnosed arthritis improved significantly from 2002 to 2006 $(P<.001)$. This improvement was driven largely by 


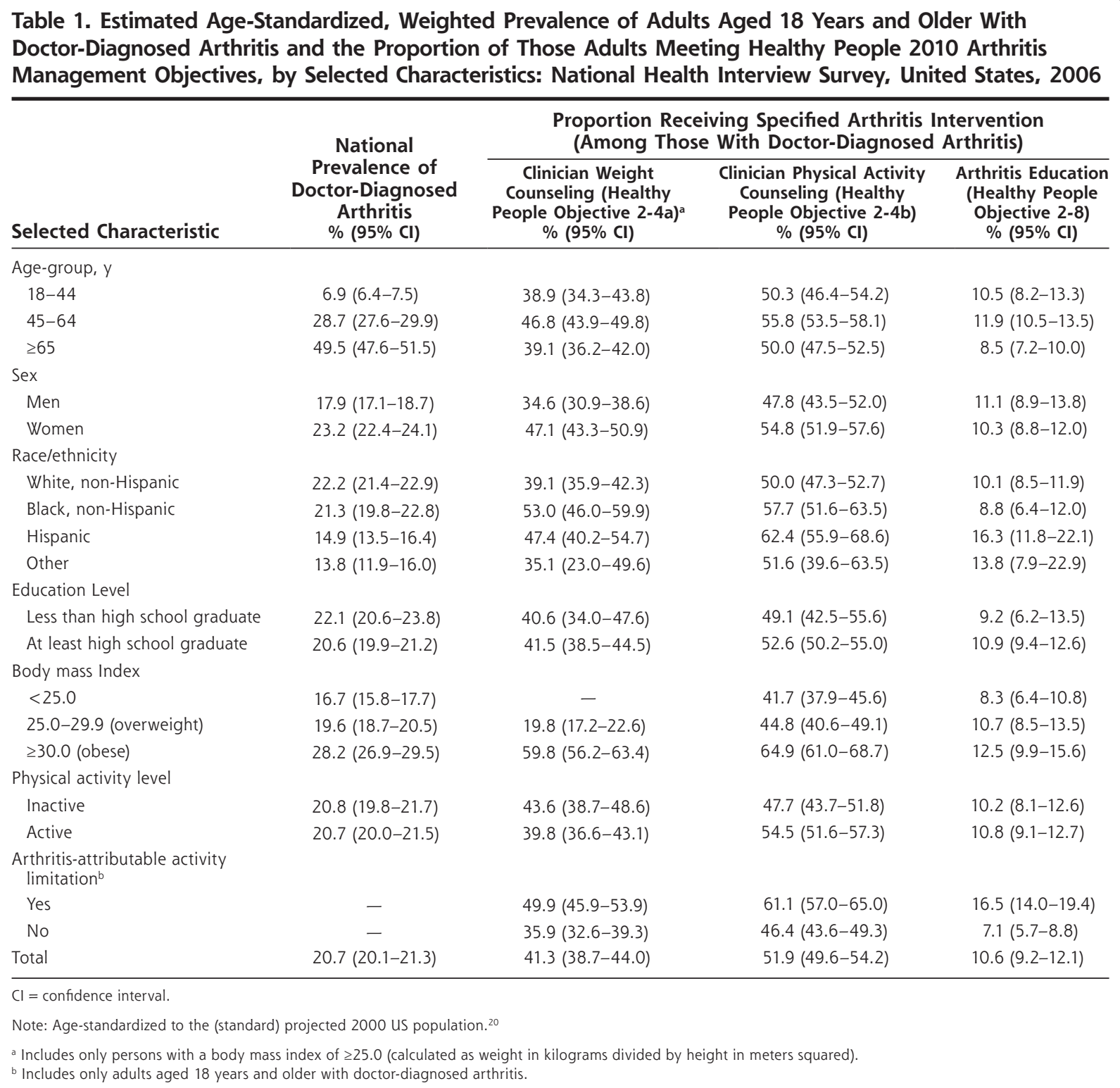

the increase observed among those who were obese (Table 2), who comprised approximately $50 \%$ of the group in both years. The receipt of weight counseling was highest among those aged 45 to 64 years and among those who were women, obese, or nonHispanic black in 2006 (Table 1). The proportion of physical activity counseling of adults with doctordiagnosed arthritis showed no statistically significant change (Table 2), with a higher proportion observed among Hispanics and those who were obese (Table 1). The proportion of arthritis education of adults with doctor-diagnosed arthritis also showed no statistically significant change (Table 2), with no particular pattern observed by selected characteristics (Table 1). Adults with arthritis-attributable activity limitations were significantly more likely to have received all 3 interventions than those without. Differences within educational and physical activity levels were minimal to none for all 3 objectives. State-level results can be viewed in Supplemental Table 1a and Table 1b, available online at http://annfammed.org/cgi/content/ full/9/2/136/DC1.

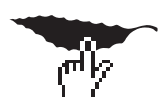

\section{DISCUSSION}

These analyses of self-reported data indicate that statistically significant improvement has been made at the national level in clinician weight counseling of obese, but not overweight, adults with doctor-diagnosed arthritis, making the HP2010 target of 46\% within 


\begin{tabular}{|c|c|c|c|c|}
\hline \multirow[b]{2}{*}{ Arthritis Management Objective } & \multirow[b]{2}{*}{ Survey Question } & \multicolumn{2}{|c|}{ Age-Standardized Proportion } & \multirow[b]{2}{*}{$\begin{array}{l}2010 \\
\text { Target } \%\end{array}$} \\
\hline & & $\begin{array}{l}2002^{\mathrm{a}} \\
\%(95 \% \mathrm{Cl})\end{array}$ & $\begin{array}{c}2006 \\
\%(95 \% \mathrm{Cl})\end{array}$ & \\
\hline Weight counseling (objective $2-4 a$ ) & \multirow{4}{*}{$\begin{array}{l}\text { Has a doctor or other health pro- } \\
\text { fessional ever suggested losing } \\
\text { weight to help your arthritis or } \\
\text { joint symptoms? }\end{array}$} & $35.0(32.8-37.2)$ & $41.3(38.7-44.0)$ & \multirow[t]{4}{*}{46} \\
\hline $\begin{array}{l}\text { Increase the proportion of adults with doctor- } \\
\text { diagnosed arthritis who receive health care pro- } \\
\text { vider (clinician) counseling for weight reduction } \\
\text { among overweight and obese persons }{ }^{b}\end{array}$ & & & & \\
\hline Weight counseling among overweight persons & & $18.1(15.8-20.7)$ & $19.8(17.2-22.6)$ & \\
\hline Weight counseling among obese persons & & $50.4(47.3-53.6)$ & $59.8(56.2-63.4)$ & \\
\hline Physical activity counseling (objective (2-4b) & \multirow{2}{*}{$\begin{array}{l}\text { Has a doctor or other health pro- } \\
\text { fessional ever suggested physi- } \\
\text { cal activity or exercise to help } \\
\text { your arthritis or joint symptoms? }\end{array}$} & \multirow[t]{2}{*}{$51.9(50.0-53.8)$} & \multirow[t]{2}{*}{$51.9(49.6-54.2)$} & \multirow[t]{2}{*}{67} \\
\hline $\begin{array}{l}\text { Increase the proportion of adults with doctor- } \\
\text { diagnosed arthritis who receive health care } \\
\text { provider (clinician) counseling for physical } \\
\text { activity or exercise }\end{array}$ & & & & \\
\hline Arthritis education (objective $(2-8)$ & \multirow{2}{*}{$\begin{array}{l}\text { Have you ever taken an educa- } \\
\text { tional course or class to teach } \\
\text { you how to manage problems } \\
\text { related to your arthritis or joint } \\
\text { symptoms? }\end{array}$} & \multirow[t]{2}{*}{$11.2(10.0-12.3)$} & \multirow[t]{2}{*}{$10.6(9.2-12.1)$} & \multirow[t]{2}{*}{13} \\
\hline $\begin{array}{l}\text { Increase the proportion of persons with doctor- } \\
\text { diagnosed arthritis who have had effective, } \\
\text { evidence-based arthritis education as an inte- } \\
\text { gral part of the management of their condition }\end{array}$ & & & & \\
\hline \multicolumn{5}{|l|}{$\mathrm{Cl}=$ confidence interval. } \\
\hline \multicolumn{5}{|c|}{ Note: Age-standardized to the (standard) projected 2000 us population. ${ }^{20}$} \\
\hline \multicolumn{5}{|l|}{$\begin{array}{l}\text { a Baseline data for national arthritis management objectives. } \\
\text { b Defined as body mass index of } \geq 25.0 \text {; body mass index calc }\end{array}$} \\
\hline
\end{tabular}

reach. No significant improvement was seen in physical activity counseling or arthritis education.

Counseling for weight loss by clinicians was also more common for those who were women, persons aged 45 to 64 years, non-Hispanics blacks, and those who had arthritis-attributable activity limitations (Table 1). These findings for clinician weight counseling are supported by studies done by Fontaine et al and Mehrota et al who, in addition, found that overweight and obese respondents were significantly more likely to report trying to lose weight if they had received weight-loss advice than if they had not. ${ }^{21,22}$ Weight counseling is important because weight loss of approximately 13 pounds has been shown to significantly reduce self-reported disability of adults with knee osteoarthritis. ${ }^{10}$ Although weight counseling is nearing the national target of $46 \%$, only $20 \%$ of overweight adults with doctor-diagnosed arthritis were being advised to lose weight in 2006, leaving considerable room for further improvement.

The lack of progress in clinician counseling for physical activity by people with diagnosed arthritis is problematic for 2 reasons: physical activity is well documented in reducing joint pain, and counseling by clinicians is one of the strongest predictors of higher physical activity levels of adults with arthritis. ${ }^{8}$ Several barriers to physical activity counseling by clinicians have been identified, including insufficient time during an appointment, unclear and nonspecific billing procedures, low reimbursement for physical activity counseling, lack of confidence in prescribing appropriate exercises ${ }^{23,24}$ and limited awareness of local evidencebased programs. ${ }^{25}$ Nevertheless, overcoming these barriers is important since several counseling interventions have been shown to be effective for increasing patients' physical activity levels. ${ }^{26-29}$ Although additional research would be needed to fully understand the current obstacles and barriers that primary care physicians are facing in counseling, training staff other than physicians (eg, nurses, medical assistants, health educators) to provide physical activity counseling either in the office setting or by telephone has been shown to be an effective alternative. ${ }^{30,31}$ Lack of confidence in prescribing exercise can be addressed by referrals to physical therapy or local community-based physical activity programs that are safe and effective for people with arthritis. ${ }^{11}$

The lack of progress in arthritis education is a missed opportunity as well. Studies show that arthritis self-management education programs can result in small to moderate reductions in pain and disability at little risk of adverse effects. ${ }^{32-35}$ The American College of Rheumatology ${ }^{6}$ is one of many organizations , $^{\text {,7-8 }}$ that recommend integrating patient self-management education as part of the counseling regime for patients with osteoarthritis so that patients can fully understand their conditions, their health outcomes, and what 
they can do to improve their quality of life. Through educational interventions, patients will be able to better manage their arthritis, reduce their pain and other symptoms, and improve their overall well-being.

Our findings are subject to limitations. First, all variables used in our analysis were self-reported rather than objectively measured. Our case finding question for doctor-diagnosed arthritis has been found to have sufficient validity for population surveillance purposes ${ }^{36}$ Height and weight may be misclassified because of social desirability (ie, women underreporting their weight, men overreporting height, etc) so proportion estimates for overweight and obese categories may be underestimated. ${ }^{37}$ Second, these Healthy People objectives may have an implied assumption that the specified intervention is relatively recent, whereas the survey questions used ask about having ever received counseling or taken an educational course or class-an indefinite time. This time discrepancy may have resulted in overestimated proportions. Finally, educational courses or classes were not further defined, so what these terms may represent in respondents' minds is unclear. Although these limitations imply that proportion estimates may be under- or overestimated, the limitations have been consistent throughout the duration of the study and likely do not affect the longitudinal trends we are reporting.

Our findings also show several strengths, including the use of a nationally generalizable survey identical to that used by HP2010 data monitors. Other strengths include a large sample size to increase precision in our results and arthritis-specific questions.

These HP2010 objectives track factors important in achieving the public health outcomes recommended by a variety of professional organizations for people with arthritis. The progress observed for weight counseling of obese adults with doctor-diagnosed arthritis is encouraging, although the overall proportion currently being reached remains far below the ideal. Lack of progress for physical activity counseling and arthritis education is discouraging. Both are important in arthritis management, because self-management skills, including regular physical activity, are essential to reducing arthritis pain and disability and improving quality of life. Because most office visits for arthritis and related conditions are with primary care physicians, ${ }^{16}$ they can have an important effect on helping their patients and achieving these HP2010 objectives. Primary care physicians do not need to do it alone, however ${ }_{i}$ using ancillary staff and referring to local resources (Supplemental Appendix 1, available online

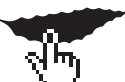
at http://annfammed.org/cgi/content/full/9/2/136/ DC1) can help address these issues without substantially adding to a physician's workload.
To read or post commentaries in response to this article, see it online at http://www.annfammed.org/cgi/content/full/9/2/136.

Key words: Arthritis; counseling; overweight; obesity; physical activity; self-management education; NHIS; BRFSS; Healthy People 2010.

Submitted April 16, 2010; submitted, revised, August 30, 2010; accepted September 21, 2010.

Support: This study was supported in part through a cooperative agreement between the Centers for Disease Control and Prevention and the Association for Prevention Teaching and Research, fellowship identification \# T-19/19-CCD07-001, FOA \# CDHM05049.

Disclaimer: The findings and conclusions in this report are those of the authors and do not necessarily represent the official position of the Centers for Disease Control and Prevention.

Presented at the BRFSS Conference, March 20-24, 2010, San Diego, California.

\section{References}

1. Centers for Disease Control and Prevention (CDC). Prevalence of doctor-diagnosed arthritis and arthritis-attributable activity limitation-United States, 2003-2005. MMWR Morb Mortal Wkly Rep. 2006;55(40):1089-1092.

2. Hootman JM, Helmick CG. Projections of US prevalence of arthritis and associated activity limitations. Arthritis Rheum. 2006;54(1): 226-229.

3. Bolen J, Sniezek J, Theis K, et al. Centers for Disease Control and Prevention (CDC). Racial/ethnic differences in the prevalence and impact of doctor-diagnosed arthritis-United States, 2002. MMWR Morb Mortal Wkly Rep. 2005;54(5):119-123.

4. Theis KA, Murphy L, Hootman JM, Helmick CG, Yelin EH. Prevalence and correlates of arthritis-attributable work limitation in the US population among persons ages 18-64: 2002 National Health Interview Survey Data. Arthritis Rheum. 2007;57(3):355-363.

5. The Arthritis Foundation and Centers for Disease Control. National arthritis action plan. A public health strategy. http://www.arthritis. org/media/Delia/NAAP_full_plan.pdf. Accessed Mar 8, 2010.

6. American College of Rheumatology Subcommittee on Osteoarthritis Guidelines. Recommendations for the medical management of osteoarthritis of the hip and knee: 2000 update. Arthritis Rheum. 2000;43(9):1905-1915.

7. Kwoh CK, Simms RW, Anderson LG, et al. American College of Rheumatology Ad Hoc Committee on Clinical Guidelines. Guidelines for the management of rheumatoid arthritis. Arthritis Rheum. 1996;39(5):713-722

8. American Academy of Orthopaedic Surgeons (AAOS). Treatment of Osteoarthritis of the Knee (Non-arthroplasty) [quideline]. Rosemont, IL: American Academy of Orthopaedic Surgeons (AAOS); 2008.

9. Shih M, Hootman JM, Kruger J, Helmick CG. Physical activity in men and women with arthritis National Health Interview Survey, 2002. Am J Prev Med. 2006;30(5):385-393.

10. Christensen R, Bartels EM, Astrup A, Bliddal H. Effect of weight reduction in obese patients diagnosed with knee osteoarthritis: a systematic review and meta-analysis. Ann Rheum Dis. 2007;66(4): 433-439.

11. Brady TJ, Jernick SL, Hootman JM, Sniezek JE. Public health interventions for arthritis: expanding the toolbox of evidence-based interventions. J Womens Health (Larchmt). 2009;18(12):1905-1917.

12. Brady TJ, Sniezek JE. Implementing the National Arthritis Action Plan: new population-based approaches to increasing physical activity among people with arthritis. Arthritis Rheum. 2003;49(3):471-476. 
13. Penninx BW, Messier SP, Rejeski WJ, et al. Physical exercise and the prevention of disability in activities of daily living in older persons with osteoarthritis. Arch Intern Med. 2001;161(19):2309-2316.

14. Hirano PC, Laurent DD, Lorig K. Arthritis patient education studies, 1987-1991: a review of the literature. Patient Educ Couns. 1994;24(1):9-54.

15. Voelker R. Guideline provides evidence-based advice for treating osteoarthritis of the knee. JAMA. 2009;301(5):475-476.

16. Hootman JM, Helmick CG, Schappert SM. Magnitude and characteristics of arthritis and other rheumatic conditions on ambulatory medical care visits, United States, 1997. Arthritis Rheum. 2002; 47(6):571-581.

17. Centers for Disease Control and Prevention (CDC). Monitoring prog ress in arthritis management-United States and 25 states, 2003. MMWR Morb Mortal Wkly Rep. 2005;54(19):484-488.

18. National Center for Health Statistics. National Health Interview Survey. http://www.cdc.gov/nchs/nhis.htm. Accessed Mar 8, 2010.

19. Centers for Disease Control and Prevention. Behavioral Risk Factor Surveillance System Survey Data. Atlanta, GA: U.S. Department of Health and Human Services, Centers for Disease Control and Prevention. 2007. http://www.cdc.gov/brfss/index.htm. Accessed Jul 30, 2010.

20. Klein RJ, Schoenborn CA. Age Adjustment Using the 2000 Projected US Population. Statistical Notes No. 20. Hyattsville, MD: National Cen ter for Health Statistics; 2001. http://www.cdc.gov/nchs/data/statnt/ statnt20.pdf. Accessed March 8, 2010.

21. Mehrotra C, Naimi TS, Serdula M, Bolen J, Pearson K. Arthritis, body mass index, and professional advice to lose weight: implications for clinical medicine and public health. Am J Prev Med. 2004;27(1):16-21.

22. Fontaine KR, Haaz S, Bartlett SJ. Are overweight and obese adults with arthritis being advised to lose weight? J Clin Rheumatol. 2007;13(1):12-15.

23. Pinto BM, Goldstein MG, DePue JD, Milan FB. Acceptability and feasibility of physician-based activity counseling. The PAL project. Am J Prev Med. 1998;15(2):95-102.

24. Woolf SH. The power of prevention and what it requires. JAMA. 2008;299(20):2437-2439.

25. Brady TJ, Jernick SL, Hootman JM, Sniezek JE. Public health interventions for arthritis: expanding the toolbox of evidence-based interventions. J Womens Health (Larchmt). 2009;18(12):1905-1917.
26. Writing Group for the Activity Counseling Trial Research Group. Effects of physical activity counseling in primary care: the Activity Counseling Trial: a randomized controlled trial. JAMA. 2001;286(6):677-687.

27. Kolt GS, Schofield GM, Kerse N, Garrett N, Oliver M. Effect of telephone counseling on physical activity for low-active older people in primary care: a randomized, controlled trial. J Am Geriatr Soc. 2007;55(7):986-992.

28. Kerse N, Elley CR, Robinson E, Arroll B. Is physical activity counseling effective for older people? A cluster randomized, controlled trial in primary care. J Am Geriatr Soc. 2005;53(11):1951-1956.

29. Grandes G, Sanchez A, Sanchez-Pinilla RO, et al. PEPAF Group. Effectiveness of physical activity advice and prescription by physicians in routine primary care: a cluster randomized trial. Arch Intern Med. 2009;169(7):694-701.

30. Peterson JA. Get moving! Physical activity counseling in primary care. J Am Acad Nurse Pract. 2007;19(7):349-357.

31. Tulloch $\mathrm{H}$, Fortier $M$, Hogg W. Physical activity counseling in primary care: who has and who should be counseling? Patient Educ Couns. 2006;64(1-3):6-20.

32. Warsi A, LaValley MP, Wang PS, Avorn J, Solomon DH. Arthritis self-management education programs: a meta-analysis of the effect on pain and disability. Arthritis Rheum. 2003;48(8):2207-2213.

33. Warsi A, Wang PS, LaValley MP, Avorn J, Solomon DH. Selfmanagement education programs in chronic disease: a systematic review and methodological critique of the literature. Arch Intern Med. 2004;164(15):1641-1649.

34. Centers for Disease Control and Prevention. Healthy People 2010. Washington, DC: US Government Printing Office; 2000.

35. Lorig K, Laurin J, Holman HR. Arthritis self-management: a study of the effectiveness of patient education for the elderly. Gerontologist. $1984 ; 24(5): 455-457$.

36. Sacks JJ, Harrold LR, Helmick CG, Gurwitz JH, Emani S, Yood RA. Validation of a surveillance case definition for arthritis. J Rheumatol. 2005;32(2):340-347.

37. Villanueva EV. The validity of self-reported weight in US adults: a population based cross-sectional study. BMC Public Health. 2001;1:11. 